\title{
A Interdisciplinaridade no Ensino É Possível? Prós e contras na perspectiva de professores de Matemática
}

\section{Interdisciplinary Teaching Is Possible? Pros and cons in perspective of a Mathematics teacher}

\author{
Daniel Morin Ocampo* \\ Marcelli Evans Telles dos Santos** \\ Vanderlei Folmer ${ }^{* * *}$
}

\begin{abstract}
Resumo
A abordagem interdisciplinar no ensino está em pauta há bastante tempo. Porém, como é a percepção epistemológica dos professores de Matemática sobre a prática interdisciplinar? Utilizamos declarações prós e contras da interdisciplinaridade escritas por 56 educadores e, sob a luz da análise textual discursiva, buscamos desvendar as formas como os professores entendem a prática interdisciplinar. Identificamos concepções simplificadas e rudimentares dos docentes pesquisados, constatamos que muitos professores apresentam concepções epistemológicas superficiais, o que traz certo receio de aceitar a prática interdisciplinar em seu cotidiano, seja por considerar que a Matemática seria desvalorizada ou por se sentirem isolados das demais áreas do conhecimento. Este estudo nos levou a acreditar que a formação inicial e continuada dos docentes, dentro da abordagem interdisciplinar, favoreceria a aceitação da interdisciplinaridade na escola por estes professores.
\end{abstract}

Palavras-chave: Interdisciplinaridade. Concepções Epistemológicas. Formação de Professores.

\begin{abstract}
The interdisciplinary approach in teaching has been in question for a long time. However, what is the epistemological perception of math teachers on interdisciplinary practice? We use pros and cons statements about the interdisciplinary approach written by 56 educators, and in the light of discursive textual analysis, we seek to uncover the ways which teachers understand the interdisciplinary practice. We identify simplified and rudimentary conceptions of the surveyed teachers and found that these epistemological gaps make the teachers afraid to accept interdisciplinary practice in their daily practices, either by considering that mathematics would be devalued or by feeling isolated from other areas of knowledge. This study led us to believe that the initial and continuous training of teachers, within the interdisciplinary approach would favor the acceptance of interdisciplinarity in school for these teachers.
\end{abstract}

Keywords: Interdisciplinarity. Epistemological Conceptions. Teachers Education.

\footnotetext{
* Mestre em Educação em Ciências pela Universidade Federal de Santa Maria (UFSM). Professor do Departamento de Matemática da Universidade Federal de Santa Maria (UFSM), Santa Maria/RS, Brasil. Endereço para correspondência: Av. Roraima, n 1000, prédio 13, departamento de Matemática, Bairro Camobi, CEP: 97105-900, Santa Maria/RS. E-mail: daniel.ocampo@ufsm.br

*:* Mestra em Educação em Ciências pela Universidade Federal de Santa Maria (UFSM). Doutoranda no Programa de Pós-Graduação em Ciências da Saúde da Universidade Federal do Rio Grande (FURG), Rio Grande/RS, Brasil. Endereço para correspondência: Rua General Osório, S/N. ${ }^{\circ}$ - sala $411-4^{\circ}$ piso da área acadêmica do Campus da Saúde, Bairro Centro, CEP: 96.200-400, Rio Grande/RS, Brasil. E-mail: marcelli_mets@hotmail.com

*** Doutor em Bioquímica pela Universidade Federal de Santa Maria (UFSM). Professor do Campus Uruguaiana da Universidade Federal do Pampa (UNIPAMPA), Uruguaiana/RS, Brasil. Endereço para correspondência: BR 472, KM 592, Caixa-postal 118, CEP: 97500-970, Uruguaiana/RS, Brasil. E-mail: vanderleifolmer@unipampa.edu.br.
} 


\section{Introdução}

Inicialmente gostaríamos de esclarecer ao leitor que este estudo não se trata de uma solução para as dificuldades existentes na prática interdisciplinar na realidade educacional brasileira. Trata-se de uma tentativa de entender as perspectivas epistemológicas sobre a interdisciplinaridade imperantes nos professores de Matemática da região oeste do Rio Grande do Sul. Objetivamos que ao fim deste estudo seja possível entender que tipos de ações colaborariam para o aprimoramento da prática interdisciplinar na Educação Básica.

A ideia de tratar os conhecimentos de forma integrada não é novidade, mesmo os gregos já buscavam essa abordagem. Entretanto, como destacado por Fazenda (1999) o movimento da interdisciplinaridade no ensino inicia sua trajetória na década de 60 na Europa, principalmente na França e na Itália, em meio a reivindicações estudantis para a melhoria da qualidade do ensino para que esse fosse o mais próximo da realidade social, política e econômica.

De lá para cá muitos estudos foram realizados e muitas obras foram publicadas, mas como citado por Pombo (2008), as pessoas que praticam, teorizam e tentam definir interdisciplinaridade ainda não sabem de fato o que vem a ser interdisciplinaridade. Ainda assim, a literatura nos dá alguns indícios de como conceituar a interdisciplinaridade. Fazenda (1979) sugere que a interdisciplinaridade é uma integração de conhecimentos parciais objetivando um conhecer geral. A mesma autora coloca que o nível interdisciplinar é oriundo de um processo de mutualidade, possibilitando o diálogo entre os interessados, o que depende de uma atitude. Em outra obra, Fazenda (1999) diz entender a atitude interdisciplinar supracitada como a síntese das atitudes de reciprocidade no diálogo, atitude de humildade diante das limitações, atitude de desafio perante o novo e atitude de envolvimento, comprometimento e responsabilidade. De forma mais sucinta, a interdisciplinaridade pode ser descrita como a "integração de objetivos, atividades, procedimentos e planejamentos, visando intercâmbio, a troca, o diálogo, o conhecimento conexo e não mais a compartimentalização das disciplinas" (CARDOSO et al., 2008, p.25).

A importância deste diálogo entre as áreas do conhecimento influenciou não apenas a pesquisa em educação, mas também a gestão educacional e a sala de aula. No contexto brasileiro, ainda que a conceituação da interdisciplinaridade não seja clara, a gestão escolar e as políticas públicas educacionais sugerem que a prática docente deve ser guiada por essa abordagem. O texto da Lei de Diretrizes e Bases da Educação Nacional (LDBEN) de 1996 
está repleto de perspectivas interdisciplinares, embora a palavra interdisciplinaridade não apareça de forma explícita. Todavia, nos Parâmetros Curriculares Nacionais (PCN) para o Ensino Fundamental a interdisciplinaridade está evidente e tais documentos indicam a importância da abordagem interdisciplinar e a incentivam por meio dos temas transversais (BRASIL, 1997a). Inclusive, quando trata da área da Matemática, o PCN recomenda a interação desses temas com o ensino de Matemática em uma ótica interdisciplinar (BRASIL, 1997b).

A abordagem interdisciplinar não é um privilégio do Ensino Fundamental, os PCN para o Ensino Médio (PCNEM) trazem já em sua apresentação que o documento se preocupa em "evitar a compartimentalização, mediante a interdisciplinaridade" (BRASIL, 2000). O termo interdisciplinaridade é repetido diversas vezes no documento e é defendido que a mesma "não tem a pretensão de criar novas disciplinas ou saberes, mas utilizar os conhecimentos de várias disciplinas para resolver um problema concreto ou compreender um determinado fenômeno sob diferentes pontos de vista" (BRASIL, 2000).

Fora das páginas da legislação, no que se refere à prática pedagógica, o professor tradicional, das mãos sujas de pó de giz e planejamentos imutáveis ao longo de seus anos de magistério, é alvo de duras críticas, acusado de falta de ousadia de tentar abraçar o novo. Os PCN, assim como diversos indícios da pesquisa na Educação, apontam que o ensino tradicional já não é mais suficiente. Coutinho et al. (2012) afirmam que o desenvolvimento científico e tecnológico causa diversos efeitos na sociedade e reflete a necessidade de transformações na educação, sendo impostos diversos desafios aos professores. Esse estudo também infere que não basta apenas capacitar ou oferecer cursos de formação continuada, é necessário que o professor perceba a necessidade de mudar de fato e não apenas no discurso (COUTINHO et al., 2012).

De acordo com Soares et al. (2014), as implicações e contribuições da interdisciplinaridade, no campo do ensino, constitui especial condição para a melhoria da qualidade, uma vez que orienta a formação global do homem. Fazenda (1979) sugere que a interdisciplinaridade depende basicamente da atitude interdisciplinar, que levaria a interação e colaboração entre as diversas disciplinas. O termo "atitude interdisciplinar" está embasado na ousadia pela busca da pesquisa, a fim de que o professor possa transformar a insegurança em construção interdisciplinar, fomentada pelas trocas e diálogos com as pessoas envolvidas (MORAES JÚNIOR, ARAÚJO e ARAÚJO, 2009). Ainda nessa linha, para Fazenda (2010) essas transformações são oriundas da reflexão sobre sua própria prática, apenas quando o 
professor/pesquisador entende e transcende sua estética e ética interior é que estará exercendo a atitude interdisciplinar.

A atitude interdisciplinar possibilita não apenas a interação de conteúdo, mas também a interação entre pessoas, já que essa perspectiva tem potencial para motivar outros professores que compõem o corpo docente. A relação interpessoal é apontada na literatura como o pilar fundamental para o ensino interdisciplinar. Jantsch e Bianchetti (2011), favoráveis à relação interpessoal na interdisciplinaridade, afirmam que a interdisciplinaridade só é fecunda no trabalho em equipe, onde se forma uma espécie de sujeito coletivo. Fazenda $(1979$, p. 57) também refere que a "interdisciplinaridade, necessidade básica para conhecer e modificar o mundo, é possível de concretizar-se no ensino através da eliminação das barreiras entre as disciplinas e entre as pessoas".

Porém, questiona-se como os professores de Matemática se posicionam frente a esta demanda. Mesmo após mais de cinco décadas de estudo e discussão sobre a interdisciplinaridade no ensino, ainda há dúvidas referentes ao seu significado e aplicação, poucos sabem ao certo de que se trata. Além disso, mesmo que a literatura mostre entusiasmo no que diz respeito à interdisciplinaridade, as avaliações de larga escala como o Exame Nacional para o Ensino Médio (ENEM) ou exemplos internacionais, como o Programme for International Student Assessment (PISA) e o Trends in International Mathematics and Science Study (TIMSS), ainda são tímidas no que diz respeito à interdisciplinaridade. A Matemática, assim como a língua materna, apresenta certo afastamento no tocante das avaliações de larga escala. Curiosamente, o senso comum e as avaliações parecem ser favoráveis ao ensino de fórmulas e teoremas em detrimento a aspectos mais sofisticados no que diz respeito ao ensino de Matemática.

Considerando esses aspectos, o presente estudo objetivou averiguar os prós e contras da interdisciplinaridade na percepção de professores de Matemática, atuantes na rede pública de ensino da região oeste do Rio Grande do Sul, para assim traçar o perfil epistemológico da interdisciplinaridade concebida por estes educadores. A carência de estudos sobre a percepção epistemológica sobre a interdisciplinaridade justifica este estudo, visto que a pesquisa no âmbito da interdisciplinaridade no ensino de Matemática traz "pouca, ou nenhuma, discussão epistemológica ou metodológica sobre a abordagem interdisciplinar no ensino de Matemática” (GONÇALVES e PIRES, 2014, p. 245).

\section{Aspectos metodológicos}


A formação continuada para professores é considerada como uma importante alternativa para contribuir com a melhoria da Educação Básica e, muitas vezes, a parceria com a Universidade contribui para estreitar as relações, favorecendo tanto a pesquisa quanto a prática docente. Assim, ao longo do ano de 2013, foram convidados professores de Matemática da rede pública das cidades gaúchas de Alegrete, Barra do Quaraí, Itaqui e Uruguaiana para participarem de encontros de formação continuada, 68 professores atuantes na área se voluntariaram a participar dos encontros. Esses cursos resultam da parceria entre a Universidade Federal do Pampa, Universidade Federal de Santa Maria, 10 ${ }^{\mathrm{a}}$ Coordenadoria Regional de Educação e Secretaria Municipal de Educação de Uruguaiana. Graças a essa parceria, os professores foram liberados, em seu horário de aula, para participar das atividades.

Os cursos, de curta duração, foram desenvolvidos em dois encontros de 4 horas cada e tinham como objetivo discutir sobre a implementação do Ensino Médio Politécnico, uma política do governo do estado do Rio Grande do Sul que propunha uma reestruturação no Ensino Médio (SECRETARIA ESTADUAL DE EDUCAÇÃO DO RIO GRANDE DO SUL, 2011). Esses encontros, desenvolvidos em cada uma dessas cidades, iniciava com uma dinâmica, na qual os professores eram convidados a escrever anonimamente em uma tira de papel os prós e contras do ensino interdisciplinar. Vale resaltar que os professores tiveram a liberdade de construir o que acreditavam ser pró ou contra, não foi sugerido aos professores categorias a priori e não era necessário que fossem declarações complemetares ou dicotômicas. Por esse motivo, as categorias apresentadas durante os resultados não são diretamente relacionadas. Os professores colocavam as tiras dentro de um balão, esses eram inflados e jogados ao chão para serem embaralhados e após estourados. Na sequência, cada professor recolhia uma das tiras do chão para leitura e discussão com os demais profissionais e mediadores do curso.

Dos 68 professores que participaram do curso, 56 aceitaram fazer parte da dinâmica. Ao término, as tiram eram recolhidas e posteriormente transcritas. Essas percepções acerca da interdisciplinaridade é que compuseram o material de análise do presente estudo.

Este é um estudo qualitativo que teve o propósito de compreender o significado atribuído pelos educadores à interdisciplinaridade. Em conformidade com Moraes (2003), a pesquisa qualitativa pretende aprofundar a compreensão dos fenômenos que investiga; a intenção é a compreensão e não testar hipóteses. Para o tratamento das percepções utilizou-se a análise textual discursiva de Moraes (2003). 
Entre os consagrados métodos de análise qualitativa estão a análise de conteúdo e a análise do discurso, transitando entre estas duas está a análise textual discursiva. O método inicia, já com o objeto de análise em mãos, pela construção de unidades de significado (MORAES e GALIAZZI, 2006). No presente artigo o objeto de análise foram as declarações dos professores, que foram agrupadas em unidades denominadas mistas (MORAES,2003) , isto é, categorias definidas a priori (estabelecidas anteriormente à análise) e categorias emergentes (criadas durante a análise para atender a todas as concepções). A interlocução empírica e teórica passou a gerar novas unidades, formando assim uma gama de unidades de análise que foram aproximadas e lapidadas. Articulando o significado das unidades pode-se aproximá-las e mesclá-las em unidades únicas, no processo chamado de categorização (MORAES e GALIAZZI, 2006). O movimento exaustivo de interpretação e produção de argumentos caracteriza a análise textual discurssiva, que ao fim produz meta-textos interpretativos que irão dar origem aos textos interpretativos, como feito no presente artigo. Para garantir o anonimato dos participantes, adotaram-se números para a identificação das declarações precedidas das letras "P" e "C", para as percepções prós e contras respectivamente.

\section{As percepções dos professores}

\subsection{Uma visão geral}

A figura $1^{1}$ ilustra, de maneira ampla, as percepções dos professores participantes do presente estudo sobre um ensino interdisciplinar. De acordo com a nuvem de palavras, a palavra Matemática é evidentementemente a mais citada pelos professores. Acredita-se que esta evidência esteja relacionada com a formação inicial dos mesmos e por ser a disciplina que ministram na escola, pois em momento algum foi solicitado que as declarações deveriam ser apontadas especificamente para o ensino de Matemática, a interdisciplinaridade foi solicitada em uma perspectiva globalizada no contexto escolar.

\footnotetext{
${ }^{1}$ Nuvem de palavras construída, a partir dos prós e contras apontados pelos professores, com o auxílio do aplicativo presente no sitio eletrônico http://www.wordle.net/.
} 


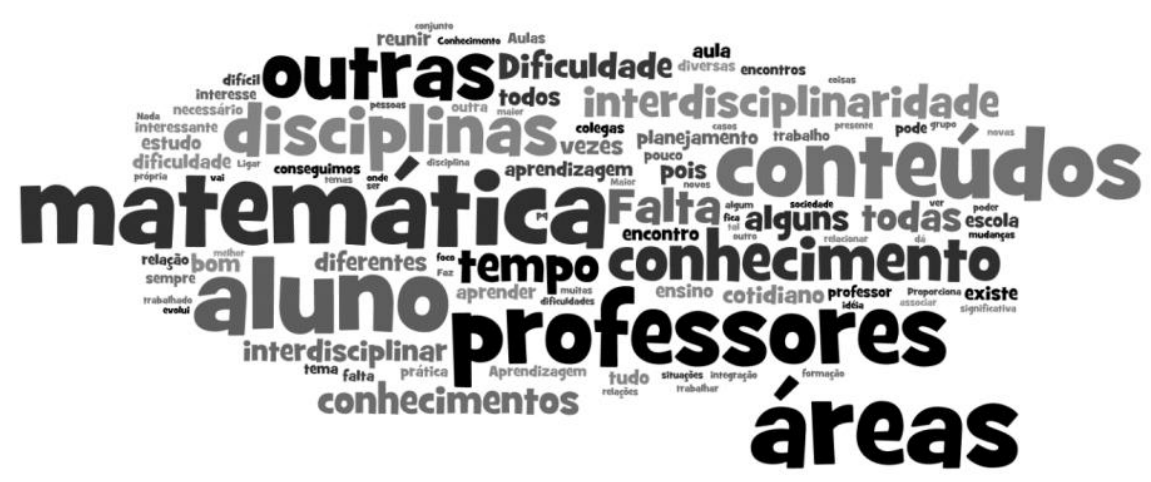

Figura 1 - Nuvem de palavras com as percepções dos professores sobre interdisciplinaridade Fonte: Dados da pesquisa (2013)

As palavras conteúdo e conhecimento também tiveram bastante destaque, isto demonstra que uma das grandes preocupações dos professores é com o conteúdo curricular a ser desenvolvido na Escola Básica, minimizando o importante impacto atitudinal para a formação dos alunos, contrariando aspectos importantes da interdisciplinaridade, considerando que "a ação pedagógica centrada na interdisciplinaridade seja um incentivo para a construção de uma escola participativa e decisiva na formação social do aluno" (GONÇALVES e PIRES, 2014, p. 251). Outro indício dessa hipótese está pautada nas poucas citações de palavras como aprendizagem, aprender e prática, o que sugere que os educadores se detêm no produto final da interdisciplinaridade, em detrimento ao processo de construção do conhecimento.

O plural do substantivo professor também foi bastante citado, uma amostra de que os docentes ressaltam o importante papel de sua mediação na perspectiva interdisciplinar. Além disso, podemos atrelar esta palavra a outras que aparecem com menos destaque, como planejamento, cotidiano, reunir, encontro e talvez até com a palavra dificuldades. No que diz respeito aos professores, a abordagem interdisciplinar demanda um grande esforço, e de fato necessita de planejamento, encontros, reuniões e etc. English (2008, p.172) destaca que "Designing appropriate interdisciplinary modelling experiences is not an easy task for teachers or researchers". Outro aspecto interessante a ser destacado é que a maioria dos educadores optou pelo plural para a palavra professores, o que nos permite entender que os docentes concebem a interdisciplinaridade no âmbito da relação interpessoal. A ênfase dada a essas palavras permite inferir que os docentes compreendem a interdisciplinaridade relacionada a mais que uma área do conhecimento e as relações interpessoais, pela tríade professores-alunos-conteúdos. De forma mais detalhada as declarações dos professores, que indicam os prós e contras do ensino interdisciplinar, serão analisadas a seguir. 


\subsection{Uma visão aprofundada}

Com auxílio da análise textual discursiva, conforme Moraes (2003), foram elaboradas seis categorias para os aspectos positivos e também seis categorias para os aspectos negativos da interdisciplinaridade citados pelos professores (Tabela 1) e como já citado, estas categorias não surgiram como opostas nem como complementares. Ressalta-se que uma mesma declaração pode estar em mais de uma categoria, por esse motivo a frequência total das categorias pró é de 76 e a frequência total dos valores contra é de 67. As porcentagens estão truncadas em duas decimais para facilitar a apresentação dos dados.

Tabela 1 - Frequência das categorias citadas pelos professores

\begin{tabular}{cccc}
\hline CATEGORIAS & $\begin{array}{c}\text { Prós } \\
(\mathbf{n = 7 6})\end{array}$ & CATEGORIAS & $\begin{array}{c}\text { Contras } \\
(\mathbf{n}=67)\end{array}$ \\
\hline $\begin{array}{c}\text { Inter-relações entre as áreas } \\
\text { do conhecimento }\end{array}$ & $\begin{array}{c}30,26 \% \\
\text { Contextualização }\end{array}$ & $\begin{array}{c}\text { Falta de tempo para encontro dos } \\
\text { professores }\end{array}$ & $20,90 \%$ \\
$\begin{array}{c}\text { Processo ensino-aprendizagem } \\
\text { mais interessante e desafiador }\end{array}$ & $15,42 \%$ & $\begin{array}{c}\text { Desvalorização da área matemática e } \\
\text { seu currículo }\end{array}$ & $14,93 \%$ \\
$\begin{array}{c}\text { Interação entre pessoas } \\
\text { Estimula habilidades e } \\
\text { competências }\end{array}$ & $9,21 \%$ & $\begin{array}{c}\text { Dstrutura curricular e administrativa } \\
\text { Priculdade de inter-relação entre os } \\
\text { conteúdos }\end{array}$ & $14,93 \%$ \\
\hline $\begin{array}{c}\text { Professores qualificados } \\
\text { Não se manifestaram }\end{array}$ & $3,90 \%$ & Formação docente deficitária & $11,94 \%$ \\
\hline
\end{tabular}

Fonte: Dados da pesquisa (2013)

A construção humana do conhecimento evoluiu ao longo dos anos no que se costuma chamar de modelo cartesiano, assim intitulado por um fragmento da obra "O discurso sobre o método" de René Descartes, publicado em 1656 (DESCARTES, 1978). A fragmentação das áreas do conhecimento é uma realidade tanto nas ciências como no ensino. Nesse sentido, o senso comum aparenta compreender a interdisciplinaridade como o inverso do chamado modelo cartesiano, ou seja, a interdisciplinaridade busca unir os conhecimentos. Por esse motivo a integração dos conhecimentos foi uma categoria a priori, isto é, já era esperada nas percepções do ensino interdisciplinar que serão analisadas a seguir. De fato, com relação aos aspectos positivos da interdisciplinaridade, na tabela 1 observa-se que em 30,26\% das declarações os docentes argumentam que a mesma proporciona a inter-relação entre as áreas do conhecimento. O professor P-6 retrata a sua realidade afirmando que, "Deve-se fazer valer a interdisciplinaridade sempre que possível. O aluno tem uma visão muito "estanque" dos conteúdos. Ele não encontra relações, nem mesmo entre um ano e outro de estudo. Ele acha que o que viu ontem não vai ver mais" (Dados da pesquisa, 2013). Não é espantosa a aparição 
desta categoria como a mais citada dentre todas, pois este é o conceito intrínseco do termo interdisciplinaridade. Talvez esta seja uma definição já gasta do termo, pois apresenta um conceito demasiadamente generalista. Podemos encarar este conceito de interdisciplinariedade perante diversas perspectivas sem ligação com a abordagem interdisciplinar no ensino, inclusive "A palavra interdisciplinaridade é constantemente resgatada pelos novos meios de comunicação que fazem dela uma utilização selvagem, abusiva, caricatural" (POMBO, 2008, p. 10). Esta definição de interdisciplinaridade, própria do senso comum, não pode ser aceita como o principal ponto favorável a abordagem interdisciplinar, pois na escola ela deve superar a simples atividade de troca de conhecimentos entre disciplinas e seus pares.

Em detrimento a essa categoria $13,42 \%$ das declarações dos docentes revelaram terem dificuldades para integrar os conteúdos, pois afirmam que a Matemática não aparece como o centro da interdisciplinaridade e que é difícil situar esta área do conhecimento em temas considerados como próprios de outras áreas. O professor C-52 retrata que "Algumas vezes é difícil interligar a matemática a outras áreas por termos na nossa cultura que a matemática é uma disciplina isolada, sem ligação com nenhuma outra" (Dados da pesquisa, 2013) e C-54 cita que "Os temas nunca partem da matemática, então tem que ser malabarista para se encaixar" (Dados da pesquisa, 2013).

Dentre os aspectos positivos mais citados encontra-se a contextualização, com uma frequência de 18,42\%. Depoimentos como "Aulas mais significativas; Problemas do cotidiano do aluno" (P-15, Dados da pesquisa, 2013) e "Estimula o aluno a querer aprender, pois sabe que tem uma contextualização e aplicação” (P-30, Dados da pesquisa, 2013) ilustram a categoria. Nota-se que os professores acreditam no potencial da interdisciplinaridade para tornar o ensino mais relevante e significativo para os alunos, de modo que os conteúdos trabalhados em sala de aula possam ter relação e ser aplicados em diferentes situações do cotidiano. Na pesquisa de Miranda e Grazire (2013) onde um caderno temático sobre saúde foi aplicado como ferramenta interdisciplinar a alunos do Programa de Integração à Educação Básica na Modalidade Educação de Jovens e Adultos (PROEJA), os autores constataram que os próprios educandos identificaram a contextualização como um fator interessante da abordagem interdisciplinar e consideraram que aprender Matemática em situações cotidianas, que não estão presas apenas a Matemática, ajuda a construir o conhecimento (MIRANDA e GAZIRE, 2013). Vale ressaltar que a interdisciplinaridade escolar, diferente da interdisciplinaridade científica, é um retorno à disciplina como um saber escolar, não se restringindo às ciências (LAVAQUI e BATISTA, 2007). Nesse sentido, o 
conhecimento construído pelos alunos em uma perspectiva interdisciplinar não se resume a "conhecimentos de laboratório", mas também a constituição do aluno como cidadão, que é capaz de aplicar o conhecimento construído no contexto escolar em seu dia a dia, daí justificase o argumento da interdisciplinaridade para a contextualização do conhecimento.

Além disso, uma parcela significativa dos professores participantes (aproximadamente $15,79 \%$ ) também citou que o trabalho interdisciplinar favorece o processo de ensino e de aprendizagem, pois esse se torna mais dinâmico, as atividades/aulas são mais atrativas, envolventes e desafiadoras, portanto, mais interessantes estimulando o aluno a aprendizagem. Por sua vez, para garantir uma aprendizagem significativa e proporcionar atividades interessantes o professor também é constantemente desafiado. As seguintes declarações exemplificam esta categoria: "O conteúdo se torna bem mais interessante, esclarecedor e dá mais condições de aprofundar" (P-7, Dados da pesquisa, 2013). "Melhoria da aprendizagem aluno/professor; Conhecimento de outras áreas; Troca de experiências" (P-41, Dados da pesquisa, 2013).

Como já referido anteriormente, a abordagem interdisciplinar no ensino supera a simples troca de conhecimento entre uma disciplina e seus pares, é sim uma complexa síntese entre conhecimentos e metodologias das áreas envolvidas que resultam em um entendimento mais holístico do tema estudado (KNIGHT, et al., 2013). Neste sentido, a prática interdisciplinar tem potencial para aliar metodologias de ensino das áreas envolvidas em um esforço para potencializar o processo de ensino-aprendizagem. A hipótese que levantamos é que os professores que citaram esta categoria visualizam estes benefícios da integração metodológica que a abordagem interdisciplinar pode proporcionar, seja vislumbrando uma prática interdisciplinar utópica ou em suas experiências didáticas.

Em contrapartida, embora os professores reconheçam a importância de integrar os conteúdos referem dificuldades para colocar em prática esta abordagem. Conforme a tabela 1, $20,90 \%$ das declarações apontaram como obstáculo a dificuldade para se reunirem com os demais professores. Este fator impede um planejamento e desenvolvimento adequado para a prática interdisciplinar, como representado na declaração do professor C-29: "Os professores pouco tem contato nas escolas. Quando um está de folga (hora atividade) o outro está em aula ou em outra escola, há dificuldades para sentarem e programarem uma aula interdisciplinar" (Dados da pesquisa, 2013). O diálogo é parte fundamental para a abordagem interdisciplinar, não apenas entre os professores, mas também entre professores e alunos e entre os próprios alunos, visto que a perspectiva interdisciplinar sofre grandes influências das 
ideias de aprendizagem social do russo Vygotsky (CHRYSOSTOMOU, 2004). Os professores participantes preocuparam-se em ressaltar a importância desta interação social em suas declarações sobre a interdisciplinaridade, a categoria "interação entre pessoas" é a quarta categoria mais citada entre os pontos positivos da interdisciplinaridade, presente em 9,21\% das declarações. Entretanto, apontar a interação pessoal apenas como um fator positivo da interdisciplinaridade leva a inferir que os docentes assumem que a interação é uma simples consequência desta abordagem, não entendem a interdisciplinaridade de um ponto de vista vygotskyano, que assume a interação social como fator crucial para a construção do conhecimento, inclusive de maneira interdisciplinar.

Além da falta de tempo para encontros necessários para o planejamento que foi citado anteriormente, os professores também apontam que a atual estrutura curricular e administrativa do ensino dificulta a abordagem interdisciplinar. Dificuldades estas que vão além das encontradas cotidianamente em sala de aula, como exemplificado pela declaração C47 "Para operacionalizar as mudanças é necessário esforço de todos, investimentos e cobranças também. Espaço para estudo na escola, cursos, reorganização de recursos humanos" (Dados da pesquisa, 2013).

Os primeiros passos para uma mudança curricular em direção a interdisciplinaridade já foram dados pelas legislações vigentes como, por exemplo, a renovação do Ensino Médio sugerida pelo Plano Nacional de Educação (PNE), que defende as práticas pedagógicas com abordagens interdisciplinares (BRASIL, 2014). Entretanto esta mudança não é tarefa simples, a cultura da disciplinariedade não está presente apenas dentro da escola, mas em todo o contexto da formação dos professores e gestores. Ressaltamos que o desenvolvimento de um currículo interdisciplinar "not only requires overcoming disciplinary cultural fault lines that impede the integration of multiple cultures, but also understanding the inherent individual and institutional conflicts that accompany such efforts" (HOLLEY, 2009, p. 254). Ainda referente a esta categoria, em sua pesquisa, Augusto e Caldeira (2007) diagnosticaram que um elevado número de docentes, cerca de $80 \%$, declararam se sentirem intimidados pela gestão escolar, que muitas vezes inibe atividades de cunho interdisciplinar, alegando que estas podem causar a indisciplina dos alunos (AUGUSTO e CALDEIRA, 2007).

Ademais, a categoria "desvalorização da área matemática e seu currículo" esteve contida em 14,93\% das declarações contra a interdisciplinaridade. C-16 e C-53 citaram respectivamente, “Atrasa o desenvolvimento do conteúdo" (Dados da pesquisa, 2013), "O estudo acaba recaindo em poucos conteúdos, utilizando, na maioria das vezes, apenas tabelas 
e gráficos" (Dados da pesquisa, 2013). Verifica-se que nesta categoria os relatos apresentados pelos professores são contraditórios, visto que nos prós do ensino interdisciplinar declararam que esse tipo de ensino proporciona a ampliação dos conhecimentos dos alunos de maneira mais interessante. Esta categoria, a segunda mais citada negativamente em relação à interdisciplinaridade, ainda evidencia que os docentes apresentam preocupações com a possível falta de conteúdo que a interdisciplinaridade traria consigo. Os mesmos acreditam que com essa abordagem os "conteúdos importantes" deixariam de ser ensinados. Desta forma conhecimentos específicos da Matemática que os alunos tivessem dificuldades deixariam de ser revisados para abordar temas comuns a todas disciplinas.

Assim, identifica-se um dos dados mais preocupantes apontados pelo presente estudo, pois os relatos permitem constatar que os docentes defendem a desagregação da Matemática das demais áreas por acreditarem que a Matemática perderia sua importância na formação dos alunos. Este medo que assola os professores pode ser oriundo da formação inicial destes docentes, visto que os conteúdos matemáticos elementares, que estes educadores ensinarão na Escola Básica, são tratados como um pré-requisito para outras disciplinas da grade curricular dos cursos de formação de licenciatura em Matemática, este tipo de conteúdo acaba sendo revisado de forma isolada, quando é revisado, e sem a perspectiva de um tratamento didáticopedagógico (VALENTE, 2013). Além disso, essa preocupação revela um desconhecimento conceitual da própria interdisciplinaridade, pois a abordagem interdisciplinar não exclui aspectos "intradisciplinares" e é capaz de fortalecer a importância não apenas o conhecimento matemático, mas de todas as áreas do saber (DRAGHICESCU, 2013). Além disso, estes profissionais sentem-se isolados dos docentes das outras áreas como é possível observar na declaração que segue, "Pois o matemático ele é direto e talvez por isso não sejam muito aceitas suas argumentações, em resumo $2+2=4$, não existe meio termo" (C-29, Dados da pesquisa, 2013) e também consideram que a metodologia interdisciplinar não proporciona conhecimentos úteis aos alunos, como exposto por C-5 "Quantidade de conteúdos não usáveis” (Dados da pesquisa, 2013).

Outro apontamento relevante é que mais fatores desfavoráveis foram apontados em relação aos aspectos favoráveis, 14,47\% das declarações dos professores apontaram apenas fatores negativos da interdisciplinaridade. Outrossim é relevante salientar que os aspectos desfavoráveis a interdisciplinaridade estão em sua maioria ligados a fatores externos a sala de aula, como falta de tempo, formação deficitária, estrutura curricular e administrativa. Uma hipótese que explicaria essas ocorrências seria a insatisfação que os professores demonstram 
com a administração escolar e com a atual estrutura curricular.

Em uma pesquisa realizada por Bizerril e Faria (2001), foram entrevistados 15 professores de diferentes áreas, atuantes em escolas públicas e privadas do Distrito Federal, questionando as dificuldades da implementação da educação ambiental de forma interdisciplinar. Nesse estudo as categorias "relações interpessoais", "resistência", "capacitação", "comprometimento" e "sistema educacional" foram apresentadas pelos professores, categorias essas similares às encontradas no presente estudo. Essa perspectiva reafirma que as dificuldades apresentadas pelos professores para a interdisciplinaridade estão alicerçadas em fatores externos a sala de aula.

Fatores relacionados à resistência dos professores quanto a abordagem interdisciplinar e a própria formação inicial foram ressaltados por vários educadores participantes. É possível inferir que a formação de educadores precisa dar atenção a aspectos da interdisciplinaridade, pois como observado no estudo de Friesen e Butera (2012), um dos argumentos dos professores para a forma como ensinam é que "Essa é a maneira que eu aprendi" (FRIESEN e BUTERA, 2012, p.366, tradução nossa). Considera-se então fundamental que os cursos de licenciatura adotem uma perspectiva interdisciplinar, não apenas no aporte teórico, mas também utilizando essa metodologia em sua estruturação. A literatura aponta a formação dos educadores como fator primordial para as mudanças metodológicas, considerando que o primeiro passo para a abordagem interdisciplinar é ensinar todos os professores (DRAGHICESCU, 2013). Como Piaget já defendia em 1978, a formação de professores é questão primordial, pois “enquanto não for a mesma resolvida de forma satisfatória, será totalmente inútil organizar belos programas ou construir belas teorias a respeito do que deveria ser realizado" (PIAGET, 1978, p.25).

\section{Considerações finais}

Muitas questões surgem quando a palavra interdisciplinaridade se torna pauta e essas inquietudes tornaram-se evidentes no estudo aqui apresentado. Pouco mais de $85 \%$ dos professores participantes elaboraram declarações sobre aspectos positivos da abordagem interdisciplinar no ensino, categorias como a inter-relação entre as áreas do conhecimento, contextualização, processo ensino-aprendizagem mais interessante e desafiador e a interação entre pessoas, puderam ser encontradas. Por outro lado, categorias como a falta de tempo para encontro dos professores, desvalorização da área da Matemática e seu currículo, estrutura 
curricular e administrativa e a dificuldade de inter-relação entre os conteúdos, compuseram os aspectos que $88 \%$ dos professores descreveram como desfavoráveis à abordagem interdisciplinar. Foi possível evidenciar que as declarações dos professores e as categorias que emergiram nesta pesquisa apresentam indícios de que muitos dos docentes pesquisados possuem concepções modestas sobre a interdisciplinaridade, visto o grande percentual de professores que pontuaram aspectos como a relação entre conteúdos e a contextualização. Esse conceito, relativamente rudimentar, pode levar os educadores a terem receio da prática interdisciplinar, considerando que esta abordagem desvaloriza os conhecimentos matemáticos, como citado por aproximadamente $15 \%$ dos docentes.

Positivamente, uma parcela dos professores demonstrou entender o benefício metodológico trazido pela prática interdisciplinar, destacando que é uma síntese de conhecimentos e metodologia. Além disso, houve também docentes que destacaram o papel da interdisciplinaridade na elaboração de um corpo de conhecimento aplicável, através da contextualização. A preocupação com a contextualização leva consigo a preocupação dos docentes com a formação cidadã do educando, pois, integrando conhecimentos escolares com características do contexto, o aluno será capaz de, no futuro, atuar de forma mais impactante na sociedade. Se incentivados pela gestão das escolas onde atuam e contando com a parceria de colegas professores, estes docentes podem construir corpos interdisciplinares que englobariam conhecimentos, contexto e metodologias de diferentes áreas, fomentando assim o aprendizado e a formação de seus alunos.

Acreditamos que esta pesquisa pôde destacar importantes fatores da percepção dos docentes de Matemática sobre a prática interdisciplinar. Os prós e contras percebidos pelos docentes são fatores a serem considerados na formação, inicial ou continuada, dos professores de Matemática, para que o medo de abraçar esta importante abordagem cesse. Ainda, é possível vislumbrar que os gestores das escolas básicas possam fazer proveito dos aspectos levantados por esta pesquisa para estratégias, para que de fato a interdisciplinaridade ocorra no ambiente escolar.

Entendemos que pesquisar a forma como as universidades abordam o tema na formação dos futuros professores pode gerar indícios de como os aspectos conceituais já descritos se estabelecem. Nesse sentido, acreditamos que estudos que se prestem a entender as formas como a abordagem interdisciplinar é tratada nos cursos de formação de professores são de suma importância, para que ocorra uma evolução nas concepções epistemológicas de docentes da área de Matemática. Defendemos que é fundamental formar professores com uma 
base sólida dos conceitos e das práticas interdisciplinares, para que as mudanças ocorram tanto dentro quanto fora da sala de aula. Teorizar sobre o tema é relevante, porém a formação deve ir além, como ensinar de forma diferente da qual aprendeu? Chegamos ao fim deste trabalho defendendo que a atitude interdisciplinar deve ser uma característica dos professores formadores de professores, para que os docentes que atuam na Escola Básica possam auxiliar cada vez mais na formação de cidadãos que enxerguem o mundo com as lentes da interdisciplinaridade.

\section{Agradecimentos}

Este estudo teve o suporte financeiro da Fundação de Amparo à Pesquisa do Estado do Rio Grande do Sul (FAPERGS) e do Programa de Pós-Graduação em Educação em Ciências da UFSM. Os autores também agradecem à Secretaria Municipal da Educação de Uruguaiana (SEMED), a $10^{\circ}$ Coordenadoria Regional da Educação (CRE) e principalmente as professoras que fizeram parte desta pesquisa.

\section{Referências}

AUGUSTO, T. G. S.; CALDEIRA. A. M. A. Dificuldades para a implantação de práticas interdisciplinares em escolas estaduais, apontadas por professores da área de ciências da natureza. Investigação em Ensino de Ciências, Porto Alegre, v. 12, n. 1, p. 139-154, 2007.

BIZERRIL, M. X. ; FARIA, D. S. Percepção de professores sobre a educação ambiental no ensino fundamental. Revista Brasileira de Estudos Pedagógicos, Brasília, v. 82, n. 200/201/202, p. 57-69, jan./dez. 2001.

BRASIL. Ministério da Educação. Secretaria de Educação Fundamental. Parâmetros Curriculares Nacionais: introdução aos parâmetros curriculares nacionais. Brasília: MEC/SEF, 1997a.

BRASIL. Ministério da Educação. Secretaria de Educação Fundamental. Parâmetros Curriculares Nacionais: matemática. Brasília: MEC/SEF, 1997b.

BRASIL. Ministério da Educação. Secretaria de Educação Média e Tecnológica. Parâmetros Curriculares Nacionais (Ensino Médio): Bases Legais. Brasília: MEC, 2000.

BRASIL. Ministério de Educação e Cultura. PNE - Lei no 13.005, de 25 de Junho de 2014. Estabelece o Plano Nacional da Educação - PNE com vigência de 2014 a 2024. Brasília: MEC, 2014.

CARDOSO, F. et al. Interdisciplinaridade: fatos a considerar. Revista Brasileira de Ensino de Ciências e Tecnologia, Ponta Grossa , v. 1, n. 1, 22 - 37, jan./abr. 2008.

CHRYSOSTOMOU, S. Interdisciplinary Approaches in the New Curriculum in Greece: a Focus on Music Education. Arts Education Policy Review, Michigan, v. 105, n. 5, 23-30, may/jun. 2004.

COUTINHO, R. et al. Percepções de professores de ciências, matemática e educação física sobre suas 
práticas em escolas públicas. Revista Ciências \& Ideias, Nilópolis, v. 4, n. 1, 1-18, jul. 2012.

DESCARTES, R. Discurso sobre o método. São Paulo: Hemus, 1978.

DRAGHICESCU, L. M. et al. Pleading for an integrated curriculum. Journal of Science and Arts, Dâmboviţa, v. 22, n. 1, p. 89-95, 2013.

ENGLISH. L. D. Promoting interdisciplinarity though mathematical modelling. ZDM - Mathematics Education, Berlin, v. 41, p. 161-181, jun./jul. 2008.

FAZENDA, I. C. Integração e Interdisciplinaridade no ensino brasileiro., 4. ed. São Paulo: Loyola, 1979. 107 p. (Coleção Realidade Educacional).

FAZENDA, I. C. Interdisciplinaridade: História, teoria e pesquisa. 4. ed. Campinas: Papírus, 1999. $143 \mathrm{p}$.

FAZENDA, I. C. Metodologia da Pesquisa Educacional. 12. ed. São Paulo: Cortez, 2010. 212 p.

FRIESEN, A.; BUTERA, G. "You Introduce All of the Alphabet... But I Do Not Think it Should be the Main Focus": Exploring Early Educator's Decisions about Reading Instruction. Early Childhood Education Journal, Pennsylvania, v. 40, n. 6, p. 361-368, 2012.

GONÇALVES, H. J. L.; PIRES, C. M. C. Educação Matemática na Educação Profissional de Nível Médio: análise sobre possibilidades de abordagens interdisciplinares. Bolema - Boletim de Educação Matemática, Rio Claro, v. 28, n. 48, p. 230-254, abr. 2014.

HOLLEY, K. The challenge of an interdisciplinary curriculum: a cultural analysis of a doctoral-degree program in neuroscience. Higher education, Alabama, v. 58, n. 2, p.241-255, 2009.

JANTSCH, A. P.; BIANCHETTI, L. Interdisciplinaridade: para além da filosofia do sujeito. 9. ed. Petrópolis: Vozes, 2011. 208 p.

KNIGHT, D. B. et al. Understanding Interdisciplinary: curricular and organizational features of undergraduate interdisciplinary programs. Innovative higher education, Queensland, v. 38, n. 2, p. 143-158, 2013.

LAVAQUI, V.; BATISTA, I. L. Interdisciplinaridade em ensino de Ciências e de Matemática no Ensino Médio. Ciência \& Educação, Bauru, v. 13, n. 2, p. 191-211, 2007.

MIRANDA, P. R.; GAZIRE, E. S. Interdisciplinaridade no Proeja: uma proposta possível no caderno temático saúde e números. Bolema, Rio Claro (SP), v. 27, n. 46, p. 481-496, ago. 2013.

MORAES, J. V. F.; ARAÚJO, A. O.; ARAÚJO, M. I. Percepção sobre a atitude interdisciplinar no curso de ciências contábeis: um estudo na Universidade norte Rio-Grandense. RCO - Revista de Contabilidade e Organizações - FEA-RP/USP, Ribeirão Preto, v. 3, n. 7, p. 127-144, set./dez. 2009.

MORAES, R. Uma tempestade de luz: a compreensão possibilitada pela análise textual discursiva. Ciência \& Educação, Bauru, v. 9, n. 2, p. 191-211, 2003.

MORAES, R.; GALIAZZI, M. C. Análise textual discurssiva: processo reconstrutivo de múltiplas faces. Ciência \& Educação, Bauru, v. 12, n. 1, p. 117-128, 2006.

PIAGET, J. Para onde vai a educação? Tradução de I. Braga. 6. ed. Rio de Janeiro: Livraria José Olympio Editora, 1978. 80 p. 
POMBO, O. Epistemologia da Interdisciplinaridade. Revista do centro de educação e letras da Unioeste, Foz do Iguaçu, v. 10, n. 1, 9-40, 2008.

SECRETARIA ESTADUAL DE EDUCAÇÃO DO RIO GRANDE DO SUL. Proposta Pedagógica para o Ensino Médio Politécnico e Educação Profissional Integrada ao Ensino Médio. Porto Alegre, RS, 2011.

SOARES, M. et al. O ensino de ciências por meio da ludicidade: alternativas pedagógicas para uma prática interdisciplinar. Revista Ciências \& Ideias, Nilópolis, v. 5, n. 1, p. 939-953, mar. 2014.

VALENTE, W. R. O lugar da matemática escolar na Licenciatura em Matemática. Bolema - Boletim de Educação Matemática, Rio Claro, v. 27, n. 47, dez. 2013.

Submetido em Abril de 2015. Aprovado em Dezembro de 2015. 